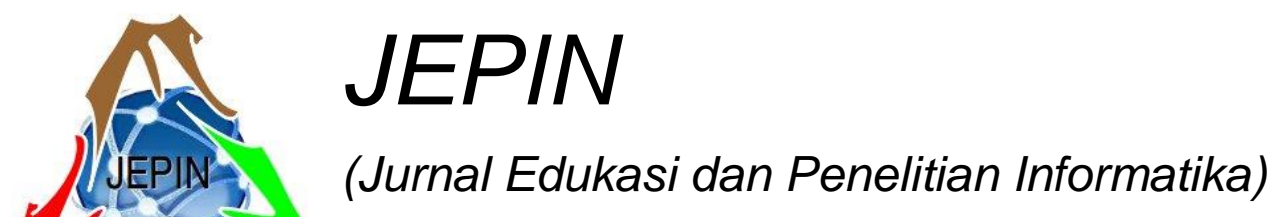

\title{
Strategi Konsep Gamifikasi dalam Aplikasi Teknologi Blockchain
}

\author{
Qurotul Aini $^{\# 1}$, Untung Rahardja ${ }^{\# 2}$, Nuke Puji Lestari Santoso ${ }^{\# 3}$, Eka Purnama Harahap ${ }^{\# 4}$, Sindy Amelia ${ }^{\# 5}$ \\ ${ }^{\#}$ Science and Technology, Universitas Raharja \\ Jl. Jenderal Sudirman No.40, RT.002/RW.006, Cikokol, Kec. Tangerang, Kota Tangerang, Banten 15117 \\ 1aini@raharja.info \\ zuntungeraharja.info \\ 3nuke@raharja.info \\ ${ }^{4}$ ekapurnamaharahaperaharja.info \\ ${ }^{5}$ sindy.ameliaeraharja.info
}

\begin{abstract}
Abstrak-Blockchain adalah tren baru yang meningkat pesat dari komunitas dan dunia usaha. Sebagai teknologi infrastruktur, dan dapat menemukan jalannya ke berbagai ranah seperti keuangan, medis, pasar digital, farmasi, dan lembaga pemerintah. Meskipun teknologi blockchain pada dasarnya dianggap sebagai fondasi Bitcoin, ia telah berkembang pesat melampaui mata uang virtual. Ini menjanjikan pembangunan kepercayaan, transparansi, dan integritas yang lebih baik tanpa pihak ketiga dan risiko penyensoran. Namun, keuntungan luar biasa ini ada harganya. Ekosistem blockchain penuh dengan masalah manusia-sentris dan ekonomis bagi para pesertanya, yang mengarah pada konsekuensi yang tidak diinginkan dalam jaringan yang terdesentralisasi. Rekayasa perangkat lunak gamified adalah bidang yang berkembang yang secara khusus memanfaatkan teknologi gamifikasi, penerapan mekanisme game dalam konteks non-game, untuk mengatasi masalah yang berhubungan dengan manusia. Saat ini tidak ada studi seputar blockchain yang telah diidentifikasi memiliki pandangan yang jelas tentang penelitian dan solusi yang ada untuk memanfaatkan gamifikasi dalam sistem blockchain yang muncul. Sebagai langkah pertama untuk mengatasi masalah ini, makalah ini membahas dan mengidentifikasi dua masalah utama berbasis manusia dalam aplikasi dan pengembangan mengimplementasi blockchain. Untuk masalah tersebut, dalam penelitian ini menggunakan metode literature review. Dengan adanya penelitian ini diharapkan gamifikasi dalam sistem blockchain dapat berjalan dengan maksimal dalam pengembangan pengimplementasinya.
\end{abstract}

Kata kunci-Gamification, Peer-to peer network, Blockchains, Decentralized software development, Smart contracts

\section{Pendahuluan}

Pada era disruptif 4.0 ini banyak generasi berlombalomba dalam menciptakan sebuah inovasi baru, hal itu membuat pertumbuhan teknologi menjadi meningkat tajam salah satunya adalah gamifikasi. Gamifikasi sendiri mempunyai arti suatu konsep yang mempunyai lapisan fitur-fitur layaknya sebuah game yang terhubung atau terintegrasi dengan blockchain [1] Gamification [2], [3] Disebabkan kurangnya pemahaman seputar blockchain, tren ini baru menjadi populer di kalangan individu dan organisasi di dunia virtual selama beberapa tahun terakhir. Perusahaan menambahkan suatu ide pada bagian sistem informasi berupa fitur game [4], [5], web dan aplikasi[6], aplikasi IoT [7], [8] Gamifikasi semakin melebarkan sayapnya hal itu membuatnya semakin dikenal oleh para pemimpin, perusahaan, dan pengembang. Untuk menjalankan tugasnya gamifikasi bergerak untuk mengembangkan keterlibatkan, motivasi, dan kinerja para pengguna,dengan cara memasukkan metode dan unsur permainan, sehingga menjadikan pekerjaan tersebut lebih produktif [9]. Gamifikasi memberikan peluang pada dunia pendidikan dengan menciptakan elemen permainan yang memfokuskan pada orientasi menciptakan ruang pendidikan baru. Hal ini efektif digunakan pada keduanya, pengajar sekolah dan pendidikan orang dewasa atau manajemen tim bisnis. Metode gamifikasi dilandasi dengan mengatasi tantangan pada saat operasionalisasi. Gamifikasi memungkinkan dapat menghilangkan kegiatan rutin dari proses pendidikan. Gamifikasi memungkinkan dapat menghilangkan kegiatan rutin dari proses pendidikan. Pada kenyataanya, setelah kita ketahui bahwa penggunaan gamifikasi semakin meluas baik di dunia nyata seperti dalam ranah pembelajaran, bisnis, serta gaya hidup.Contohnya, keistimewaan berbelanja online dengan menggunakan kartu kredit, media sosial (seperti, parameter kemajuan Linkedin), lingkungan e-learning (misalnya Code Academy yang menggunakan sistem motivasi dari berbagai prosedur permainan untuk membuat pelajar tetap terlibat dan diberi insentif untuk terus belajar. ), aplikasi seluler, dan banyak lagi. Oleh karenanya, gamifikasi memiliki kekuatan untuk menciptakan teknologi lebih menarik dan berdasarkan pada keterlibatan pengguna terhadap apa yang diinginkan. Inilah sebabnya mengapa berbagai industri telah berubah 
ke arah gamifikasi dan menggunakan prinsip desain game untuk mengembangkan keikutsertaan pengguna dan membatasi churn pelanggan. Dalam hal yang dimaksud, di sisi lain gamifikasi terdapat manfaat serta masalah yang berkaitan langsung dengan manusia dalam teknologi blockchain. Terdorong akan hal tersebut, karya ilmiah ini mengkaji permasalahan tentang pengimplementasian gamifikasi di dalam sistem blockchain serta mengedukasi masyarakat seputar gamifikasi dalam sistem blockchain. Artikel ini bertujuan sebagai wadah forum untuk mengatasi tantangan yang bersumber pada manusia yang ditimbulkan dari teknologi ini dan "cara" dari gamifikasi sistem blockchain dapat secara mendasar mengubah bagaimana nilai bisnis yang lebih baik diciptakan dan direalisasikan. Pekerjaan ini terutama ditujukan kepada peneliti untuk disiplin untuk menjelaskan arah penelitian dan praktik di masa depan di bidang blockchain gamifikasi.

Dengan adanya penelitian ini diharapkan gamifikasi dalam sistem blockchain dapat direalisasikan dengan baik [10], serta diharapkan dengan adanya penelitian seperti ini masyarakat bisa lebih mengetahui lagi seputar perihal gamifikasi dalam sistem blockchain. Sisa dari makalah ini disusun sebagai berikut: Bagian II menyajikan pekerjaan terkait tentang penerapan gamifikasi dalam tugas-tugas perangkat lunak dan rekayasa sistem dan memberikan latar belakang yang diperlukan tentang komponen-komponen blockchain. Bagian III mengidentifikasi masalah yang berpusat pada manusia dalam sistem blockchain dan menguraikan model gamified yang diusulkan. Bagian IV membahas aspekaspek yang terkait dengan mekanisme game dan daftar awal yang disarankan untuk sistem blockchain. Bagian V memberikan kesimpulan dan pekerjaan masa depan.

\section{STUDI LITERATUR}

\section{A. Gamifikasi dalam rekayasa perangkat lunak}

Teknologi pada dunia pendidikan [11], [12] berkembang setiap tahunnya dengan cepat dan terciptalah teknologi baru sebagai media dalam proses pembelajaran yang dinamakan dengan gamifikasi [13], [14], [15], oleh karena itu penelitian ini membahas bagaimana mencari solusi atas masalah yang bersangkutan dengan manusia dari segi pengembangan serta pemeliharaan rekayasa perangkat lunak. Dapat diartikan bahwa rekayasa perangkat lunak terlalu terfokus pada proses kinerja manusia dimana kinerja tersebut berkolaborasi dengan lingkungan yang tidak stabil. Dengan permasalahan yang ada terdorong para peneliti atau para ahli dalam bidang perangkat lunak menciptakan teknologi baru dengan nama gamifikasi, teknologi ini dapat mempermudah manusia dalam kegiatan keseharian nya dari segala aspek. Salah satu aspek tersebut pada instansi pendidikan, karena di dunia pendidikan dibutuhkan perangkat lunak sebagai media edukasi dalam pekerjaan. Dapat dilihat perkembangan gamifikasi dalam kurun waktu beberapa tahun terakhir sudah dikembangkan oleh para peneliti atau ahli perangkat lunak untuk dapat dihubungkan ke bidang lainnya dan diaplikasikan terhadap lingkungan. Dari penelitian paper sebelumnya sudah dijelaskan teknologi gamifikasi sudah dimanfaatkan pada aplikasi dan bidang lainnya, dengan tujuan mengembangkan proses yang lebih mudah dan meningkatkan kualitas dari segi teknik sering disebut sebuah proses konvensional. Dimana proses tersebut terbagi menjadi beberapa bagian seperti untuk memperoleh [16] sebuah persyaratan dan sebuah prioritas [17], melakukan pencarian perangkat lunak [18] [19], menguji perangkat lunak [20], proses sebuah perangkat lunak [21] [22], pengelolaan proyek[23] dan juga berbagai pengetahuan baru yang dapat dibagikan[24]. Hasil pencapaian yang didapat dari penelitian dengan konsep proses kerja lebih meningkat dan bermutu [9],[7] dan melakukan percobaan untuk mendorong [25] pemanfaatan penerapan teknologi gamifikasi terhadap kegiatan pada sistem dan dalam rekayasa perangkat lunak. Dalam aktivitasnya di dunia IT, gamifikasi blockchain menghadirkan sebuah sistem pembelajaran digital seperti IDu dan IMe. IDu menggunakan SSO (Single Sign-On) dimana pengguna dapat masuk dengan menggunakan google yang sudah terhubung dengan Rinfo. IMe iMe (Media iLearning) pada iMe gamification atau Media iLearning terdapat metode SC (Special Contribution) yang diperoleh siswa sebagai tanda reward keaktifan mahasiswa.

\section{B. Blockchain untuk Lingkungan gamifikasi}

Penggunaan cryptocurrency digunakan sebagai media untuk bertransaksi uang digital secara online dengan menggunakan jaringan internet. Sejalannya dengan perkembangan teknologi, manusia telah memanfaatkan cryptocurrency sebagai platform pada blockchain dengan membuat teknologi gamifikasi yang bertujuan menjadi solusi dalam memecahkan masalah. Teknologi tersebut berupa sebuah aplikasi seperti HoToKeN [26], Sandblock [25], dan POIN Token [25] merupakan contoh sistem dalam mengelola program penghargaan serta loyalitas pada blockchain. Dimana para peneliti sudah membenarkan bahwa blockchain dalam pemanfaatan kinerja memiliki potensi untuk mengubah cara bisnis lebih intensif dan dapat melibatkan para pelanggan untuk dapat mengakses program yang berkaitan dari sini terlihat bahwa penggunaan gamifikasi memberikan loyalitas terhadap pihak yang bersangkutan. Karena pada sebelumnya terlihat bahwa program tersebut hanya memberikan loyalitasnya terhadap perusahaan dengan mendapatkan keuntungan sebesar-besarnya tanpa memikirkan keuntungan dan kenyaman terhadap para peserta tanpa memberikan hadiah berupa penghargaan dari kinerja yang mereka berikan terhadap perusahaan. Dari permasalahan program tersebut perusahaan mencoba memanfaatkan teknologi blockchain dalam perubahan sistem sebelumnya menjadi lebih baik dalam segala hal yaitu pencatatan data yang akurat, kualitas dari segi keamanan, terbuka (transparan), dan proses transaksi lebih cepat dan tepat, dimana sistem tersebut bekerja dengan 
sendiri tanpa campur tangan pihak ketiga dan juga terpusat serta terpadu dengan perkembangan dunia. Teknologi blockchain sudah banyak dimanfaatkan di dunia industri, karena sistemnya bisa dipakai dalam berbagai hal dan membawa keuntungan dari segi penghargaan yang sudah diberikan kepada peserta, pengadaan vendor dan penggunaan akhir, dimana teknologi gamifikasi membawa perubahan atas produk yang telah dihasilkan dengan membawa perubahan yang lebih baik pada dunia industri. Disini kerugian terbagi menjadi dua : (1) blockchain merupakan pilihan utama yang baik dalam menyimpan data dengan jumlah besar, seperti data lama yang diperbaharui dengan contoh (hadiah atau poin). Dimana sebagian besar dalam sistem gamifikasi berbaur blockchain dapat membawa proses perpindahan database yang terfokus saat ini untuk mengelola sistem yang ada di gamifikasi (menangani lencana, poin, reputasi dan lainnya.) ke sebuah buku besar publik dengan implementasi berantai kunci. Namun dalam kasus perpindahan (migrasi) sistem terpusat (database) menuju blockchain yang sudah terimplementasi dengan publik, menghasilkan sistem secara signifikan kecepatan yang lambat pada throughput dan biaya yang lebih tinggi dari sistem terpusat, karena pada melakukan transaksi dibutuhkan pengeluaran yang tinggi atau pembayaran mahal agar terverifikasi dalam jaringan. (2) Pemahaman mengenai teknologi blockchain yang minim, dimana pada permasalahan sebelumnya pada gamified belum terselesaikan agar si peserta mendapatkan loyalitas atau penghargaan secara otomatis pada sistem dari kinerja fokus utama dalam paper. Startup merupakan perusahaan yang masih terbilang baru untuk dapat berkembang di pasar, dimana startup sendiri sudah memanfaatkan teknologi blockchain dalam konsep bisnis yang menjadi acuan pada bisnis mereka. Salah satunya arcade city [25] merupakan suatu sistem dalam basis blockchain sebagai media memecahkan masalah bereputasi desentralisasi melalui lapisan gamification opt-in. Konsep menaikkan level pada profil pengemudi merupakan suatu cara dengan memberikan fasilitas seperti keamanan yang membuat si pengendara mobil menjadi senang tanpa adanya kecemasan. Aturan tersebut seperti pemberian poin yang didorong komunitas dalam menciptakan kontak pintar berbau blockchain ethereum [25]. Proyek blockchain baru dibuat disebut juga Fund Fantasy [25] dimana media tersebut memberikan penawaran dengan sistem sederhana pada platform Ethereum [25] mendorong para investor untuk menerapkan sistem tersebut agar dapat bersaing di pasar nasional dan internasional. Sistem tersebut terinspirasi dari prinsip fantastis olahraga menjadi acuan pengguna dapat mengundang teman mereka di dalam permainan tersebut untuk memainkannya dengan tujuan mengumpulkan hadiah dan menerima hadiah tersebut.

\section{Latar Belakang Komponen Blockchain}

Teknologi blockchain tidak hanya terfokus pada satu bidang saja. Tetapi dapat menghubungkan infrastruktur multi-bidang termasuk kriptografi, algoritma konsensus terdistribusi, ekonomi model, dan jaringan peer-to-peer [27]. Sebuah blockchain dapat dilihat sebagai bentuk:

1. Sebuah strategi untuk menciptakan sistem yang tidak dapat diubah, oleh semua participants dalam jaringan siaran.

2. Sebuah strategi untuk menyatakan kesepakatan sebagai masukan sistem yaitu, memvalidasi transaksi.

3. Strategi untuk mendorong kesepakatan.

4. Penggunaan jaringan broadcast bertujuan untuk memastikan bahwa semua peserta di blockchain yang memproses urutan transaksi dan ditandatangani (sebagian besar jaringan blockchain menggunakan elips kurva algoritma tanda tangan digital (ECDSA) [28] untuk ini). Pengimplementasian setiap transaksi menyebabkan berjalannya proses yang maksimal. Dari hal tersebut mendapatkan hasil perubahan status dalam sistem informasi yang diwakili oleh blockchain.

Kekuatan keamanan yang dijanjikan oleh jaringan blockchain mendapatkan fakta bahwa setiap orang dapat memonitor seluruh pencarian status sistem. Pada kenyataannya di lapangan, tidak siapapun dapat memonitor. Untuk tujuan inilah terdapat kelas pengguna / node khusus, yang dikenal sebagai mining dalam Proofof-Work atau pembuat dalam Proof-of-Stake metode, yang diberi dorongan untuk memverifikasi kebenaran setiap transaksi (termasuk pembuatan blok / kontrak dan transaksi perubahan status).

Insentif dalam sistem blockchain dapat dalam bentuk Proof-of-Stake (PoS) atau Proof-of-Work (PoW). Dalam metode berbasis PoW (Bitcoin menggunakan bukti Hashcash sistem kerja), mining harus dapat memecahkan teka-teki permasalahan matematika. Pada langkah ini, menghitung maju matematika jaringan Peer to Peer dapat ditemukannya masalah, yaitu menemukan ID untuk blok berikutnya di blockchain dan pada saat itulah node penambang diaktifkan. Jaringan Peer to Peer adalah suatu sistem pendistribusian dari catatan transaksi menuju kepada user yang terhubung pada jaringan blockchain [29]. Perhitungan ini membutuhkan ID yang sebelumnya untuk menghitung ID selanjutnya, dan ini membuat nya tidak dapat diubah karena jika seseorang ingin mengubah kunci dia perlu menghitung ID dari setiap blok sebelumnya. Setiap node berpartisipasi dalam konsensus proof-of-work bersaing dalam memecahkan masalah matematika. Node pertama untuk memecahkan masalah blok akan dihargai, dan dia mendapatkan keistimewaan untuk menambahkan / menerima blok ke blockchain.

Di sisi lain, metode berbasis $\mathrm{PoS}$, menggunakan pendekatan yang sangat berbeda saat memvalidasi transaksi, akibatnya memberi insentif kepada pengguna yang melakukannya. Metode ini dibangun di atas kritik PoW karena itu konsumsi tinggi energi dan sumber daya komputasi. Maka dari itu, diusulkan alih-alih menghitung masalah matematika sebagai dalam bukti kerja untuk menghasilkan blok baru, pemilik berikutnya kunci akan dipilih dengan cara 
deterministik di mana peluang orang yang dipilih tergantung pada kekayaan (itu adalah taruhan - saldo di dompet mereka). Pekerjaan berbasis PoS validasi oleh pengguna biasanya dianggap sebagai pemalsuan atau pencetakan sebagai kebalikan dari mining dalam metode bukti kerja (namun, banyak sumber daya yang saling bertukar menggunakan istilah mining untuk kedua PoW dan metode PoS, termasuk makalah ini). Di PoS tidak ada reward untuk menciptakan blok baru, jadi bukan yang minters mengambil payment (biasanya sebanding dengan saham yang diadakan di mereka dompet, dan dalam bentuk biaya transaksi) untuk mengesahkan kebenaran setiap transaksi. Setiap kesalahan (disengaja atau jika tidak) dibuat dalam menyatakan kebenaran akan mengakibatkan hilangnya taruhan.

\section{Implementasi gamifikasi pada Blockchain}

Perubahan teknologi tidak dapat ditebak karena dari tahun ketahun berikutnya banyak mengalami perubahan tanpa adanya keterbatasan, perubahan tersebut membawa adanya inovasi baru untuk dapat menciptakan teknologi yang lebih fleksibel dan efektif dalam meringankan pekerjaan manusia seperti teknologi blockchain. Dimana teknologi tersebut masih populer untuk diperbincangkan dalam setiap bidang pemanfaatan nya. Teknologi blockchain dikenal dengan sebutan buku besar, dimana pada buku tersebut dapat melakukan pencatatan transaksi secara terbuka dengan database yang sudah desentralisasi atau sistem yang tidak membutuhkan perantara terhadap pihak ketiga dalam melakukan transaksi [25] Keunggulan blockchain terlihat dari segi keamanan terhadap pengguna dalam keamanan data yang tidak dapat dirusak. Sebelumnya blockchain hanya digunakan sebagai media transaksi uang digital (bitcoin) tanpa membutuhkan adanya pihak ketiga, oleh sebab itu banyak peneliti yang sudah menggunakan teknologi blockchain pada bidang lainnya. Dimana dalam blockchain terdapat beberapa sistem seperti:

1) Pengguna yang Tidak Berfungsi: Blockchain memiliki fungsi dengan sifat yang sangat bergantung dalam partisipasi penggunaan secara aktif. Dimana sistem desentralisasi berjalan dengan adanya pengguna, apabila tidak ada pengguna maka sistem tersebut tidak termasuk pada jaringan apapun. Namun pengalaman dari penggunaan data yang tidak dapat berfungsi menjadi permasalahan prosesnya jalannya sistem terhadap kesuksesan bisnis pada blockchain baik dalam penggunaan secara koin cryptocurrency atau layanan noncryptocurrency. Dimana permasalahan khusus tersebut bersumber dari proses validasi pada blok bawahan (model insentif) menyebabkan masalah penggunaan pada sistem secara tidak langsung. Blockchain mempunyai manfaat pada publik, dimana teknologi tersebut dapat digabungkan ke dalam sistem yang sudah ada sebelumnya menjadi lebih berkualitas dan fleksibel seperti contoh data seseorang dalam mengetahui bahwa data tersebut punya nya dengan memiliki sebuah bukti yang dapat diakses secara mudah dan terjamin keasliannya atau seseorang yang melakukan sebuah transaksi tanpa membutuhkan pihak ketiga. Namun dibutuhkan tenaga ahli untuk dapat memanfaatkan sistem tersebut pada blockchain.

2) Perkembangan Aset yang Tidak Berjalan: Bekerjanya sistem desentralisasi pada blockchain berjalan di jaringan P2P yang terdapat di komputer, dimana sistem tersebut berjalan tanpa perlu adanya pihak ketiga. Namun sistem ini diharuskan menggunakan sebuah token agar sistem yang telah dibuat dapat berjalan dengan baik dan aktif. Lebih spesifiknya sistem blockchain pada aplikasi desentralisasi memiliki kriteria untuk dikembangkan[30] :

1. Dalam sebuah aplikasi memiliki sifat open-source : Dimana sistem tersebut beroperasi secara mandiri dan tanpa entitas dalam pengendalian mayoritas sebuah token berpenghasilan.

2. Catatan yang berbentuk aplikasi harus tersimpan secara kriptografis: Maksudnya adalah data tersebut tersimpan dan dilindungi menggunakan sebuah kode dengan desentralisasi pada blockchain.

3. Aplikasi dengan menggunakan token dalam mewakili aset: Dimana berbentuk cryptocurrency dalam bitcoin dan token lainnya seperti properti berbentuk kotak pintar (kupon aman) tidak terpisah, untuk dapat mengaksesnya dibutuhkan akses pada aplikasi.

4. Dalam aplikasi menghasilkan token: Menurut a dalam algoritma pada konsensus kriptografi pada standar (PoS atau PoW) bertindak sebagai bukti nilai, node (pengguna) dengan memberikan kontribusi terhadap aplikasi.

Persyaratan diatas menjadi masalah kedua yang sudah teridentifikasi pada sistem blockchain dalam mengeluarkan Token yang terkait pada aspek tokenisasi aplikasi bawaan, yang memberikan dampak negatif seperti permasalahan ekosistem.

Pada kenyataannya, pengguna blockchain cenderung menimbun token mereka (mis., mata uang) sebagai produk investasi, bukan media moneter untuk dibelanjakan baik jasa maupun barang, membuat peluang dari model bisnis berbasis rantai kunci dengan tingkatan yang lebih kecil keterlibatan di antara peserta. Fenomena ini terutama token tersebut (terutama mata uang virtual) tidak dilihat sebagai metode pembayaran yang ideal karena ketidakstabilan mereka persepsi pasar. Akibatnya,ini masalah bertindak seperti motivasi bagi orang-orang yang terlibat untuk secara aktif terlibat dalam memindahkan token dalam sistem untuk monetisasi dan peluang yang lebih baik.

3) Solution: Stealth Gamification: Pengimplementasian yang mendasari untuk menghubungkan bukti kepemilikan ataupun kumpulan mining bukti kerja blockchain dengan sistem permainan yang tepat. Dengan metode ini, pengguna tidak perlu mengetahui secara spesifik bahwa mereka melakukan mining dalam pengertian dapat merusak pikiran dengan 
merangkum detail teknis sambil mengalihkan tugas ke lingkungan yang lebih menyenangkan. Melalui sistem mining pada gamifikasi ini, pengguna/konsumen dapat menyimpan dana sebagian saham mereka untuk verifikasi blockchain saat terlibat dengan tugas yang menyenangkan dan dengan demikian mengumpulkan penghargaan dan poin untuk blok yang diselesaikan.

Sebagian besar karya mutakhir Bitcoin diyakini memiliki atribut yang gagal. Selain itu, lapisan ini harus dapat menyeluruh sistem yang tepat untuk melakukan gamifikasi "token pengeluaran" sebagai sistem insentif tambahan untuk membantu sistem menjadi memadai dan mengalir secara ekonomis (menangani masalah kedua). Dengan mendapatkan solusi, perusahaan mendapatkan keuntungan dari pemasaran mandiri dan melibatkan pengguna sambil membantu orang biasa yang mencari aksesibilitas ke sistem blockchain tanpa harus memahami teknologi atau teori apa pun di baliknya.

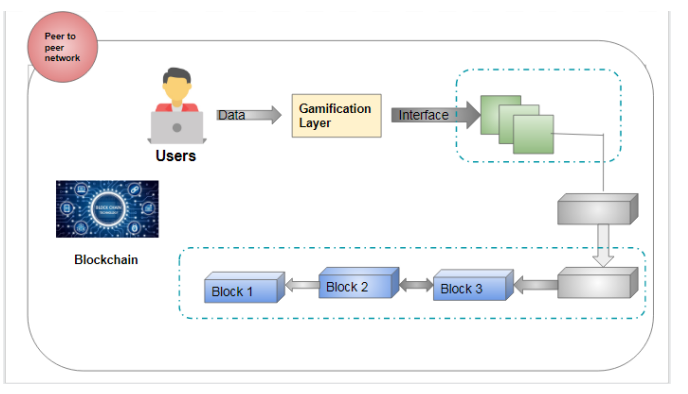

Gambar. 1 Konsep gamifikasi blockchain

Gambar 1 menunjukkan pandangan konseptual dari model yang diusulkan dan komponennya dalam sistem blockchain yang khas. Dalam jaringan blockchain setiap pengguna dapat membuat dan menyebarkan transaksi (data) yang mereka kendalikan. Dalam hal ini, transaksi memungkinkan dapat memiliki daftar input yang di setiap masing-masingnya terfokus pada nilai yang sudah ada (dicontohkan sebagai output dari transaksi sebelumnya), dan daftar output yang tidak kosong (output yang digunakan untuk aplikasi). Sebuah transaksi yang ditandatangani secara digital pada setiap masukan, yang dapat diverifikasi dengan kunci publik yang juga disertakan dalam masukan. Inti dari kunci publik harus cocok dengan yang ditujukan untuk keluaran yang dirujuk. Struktur ini berdiri sendiri, dan validitasnya dapat diverifikasi oleh siapa saja yang berinteraksi dengan dashboard lapisan gamifikasi.

Bagi para mining mengerti tentang teknis merupakan suatu hal yang penting, karena dengan memiliki keterampilan yang dibutuhkan maka dapat diperlakukan secara adil (mungkin, dengan tingkat taruhan yang lebih tinggi). Dengan demikian, lapisan gamified harus mengenali fitur ini dengan menyematkan penyesuaian yang tepat karena secara infrastruktur penting bagi keberlanjutan sistem blockchain untuk memberi insentif kepada pemain profesional (yaitu mining )
Dari perspektif yang lebih teknis, penambahan gamified yang diusulkan dapat dibangun dan ditangani melalui kontrak pintar menggunakan bahasa khusus domain, seperti Solidity 1, yang cocok untuk platform hosting (tentu saja, dapat dicapai melalui metodologi lain). Untuk memberikan peta jalan implementasi termodulasi yang lebih baik dan membayangkan, Tabel 1 menunjukkan kontrak template.

TABLE I

SMART CONTRACTS IMPLEMENTASI GAMIFIKASI

\begin{tabular}{|l|l|c|}
\hline \multicolumn{1}{|c|}{ Kontrak } & \multicolumn{1}{|c|}{ Tujuan } & \multicolumn{1}{c|}{$\begin{array}{c}\text { Sebagai } \\
\text { Penyimpanan }\end{array}$} \\
\hline Penyelenggara & $\begin{array}{l}\text { Kontrak utama sebagai } \\
\text { sumber dari lapisan } \\
\text { gamifikasi }\end{array}$ & \multicolumn{2}{|c|}{} \\
\hline Pengguna & $\begin{array}{l}\text { Menjaga segala yang } \\
\text { berkaitan dengan tugas } \\
\text { serta menyimpannya }\end{array}$ & $\sqrt{ }$ \\
\hline Tugas & $\begin{array}{l}\text { Mengurus segala } \\
\text { sesuatu yang berkaitan } \\
\text { dengan tugas serta } \\
\text { menyimpan data tugas }\end{array}$ & $\begin{array}{l}\mid \\
\text { Menjaga segala sesuatu } \\
\text { tentang i serta melacak } \\
\text { data oleh setiap } \\
\text { pengguna (saya } \\
\text { mewakili mekanik } \\
\text { game seperti point) }\end{array}$ \\
\hline Game
\end{tabular}

Smart Contract berfungsi sebagai pengontrol serta penyimpanan antara pengguna dan proses validasi yang terkait dengan lingkungan gamified. Kontrak pertama yang disebut penyelenggara bekerja sebagai titik pusat dari lapisan gamified dan karena itu berinteraksi dengan setiap kontrak lainnya. Ini juga menyediakan sarana untuk merangkap meta-data yang dibutuhkan. Smart Contract berfungsi sebagai pengontrol serta penyimpanan antara pengguna dan proses validasi yang terkait dengan lingkungan gamified. Kontrak pertama yang disebut penyelenggara bekerja sebagai titik pusat dari lapisan gamified dan karena itu berinteraksi dengan setiap kontrak lainnya. Ini juga menyediakan sarana untuk merangkap meta-data yang dibutuhkan.

Segala sesuatu mengenai pengguna, menyimpan pengguna bentuk informasi yang relevan pribadi, sistem yang terkait, untuk insentif gamified berhubungan dengan pemegang kontrak. Bagi pengguna lain informasi tersebut diberikan jangka waktu. Tugas kontrak adalah mengelola semua tugas yang ada dan yang akan datang. Mekanik Permainan kontrak menangani data gamification untuk setiap pengguna, sebagai akibat insentif dari keterlibatan mereka dengan proses penambangan, yaitu game. Data ini (misalnya, taruhan) diterima saat menyelesaikan satu blok dan hanya dapat digunakan di dalam sistem untuk hadiah atau layanan dari pengguna lain. 


\section{HASIL DAN PEMBAHASAN .}

\section{A. ROQ1;. Bagaimana sistem gamifikasi di dalam ruang lingkup blockchain?}

Dalam gamifikasi suatu masalah terdapat berbagai aspek yang harus dipertimbangkan dan didukung [25], termasuk: memahami masalah dan mengetahui target audiens lingkungan yang di-gamifikasi, menyesuaikan konteks untuk memenuhi kebutuhan yang berbeda. jenis kepuasan pemain, dan yang terpenting memiliki bermakna mekanisme permainan yang untuk menerapkan konsep gamifikasi. Mendefinisikan mekanisme gamifikasi (yaitu dinamika yang sesuai untuk mengambil keuntungan untuk melibatkan dan memotivasi pemain dengan cara terbaik) adalah bagian paling menantang dari model gamified saat kami berusaha mengubah gamifikasi menjadi aset utama sambil menyelesaikan masalah manusia yang terkait. Masalah ini menjadi lebih buruk karena sifat segar dari sistem blockchain yang bertentangan dengan aplikasi web tradisional. Untuk membantu mendapatkan mekanisme game khusus blockchain yang sesuai, kami mengkonsolidasikan berbagai elemen desain gamifikasi dan demografi untuk menjelajahi ekosistem blockchain. Dalam hal ini, kami meninjau literatur tentang desain game dan mengidentifikasi elemen motivasi yang telah dimasukkan dalam desain gamifikasi dalam berbagai studi terbaru, terutama yang terkait dengan lingkungan pengembangan perangkat lunak.

TABLE II

DAFTAR SITEM GAMIFIKASI YANG DI SARANKAN

\begin{tabular}{|l|l|}
\hline Mekanika & Efek / manfaat \\
\hline $\begin{array}{l}\text { Peristiwa } \\
\text { sosial }\end{array}$ & $\begin{array}{l}\text { Mengintegrasikan peristiwa dunia nyata yang } \\
\text { dilakukan oleh pengguna dengan blockchain } \\
\text { untuk mempromosikan Internet nilai. } \\
\text { Misalnya, membuat posting di Twitter / } \\
\text { Instagram / Facebook tentang perusahaan / } \\
\text { layanan blockchain oleh pengguna, atau } \\
\text { mengundang teman harus diakui }\end{array}$ \\
\hline dihabiskan & $\begin{array}{l}\text { Kemajuan yang dan pelacakan token (aset) } \\
\text { yang dibelanjakan pengguna. }\end{array}$ \\
\hline Poin & $\begin{array}{l}\text { Penghargaan ekstrinsik dan statistik } \\
\text { pencapaian (taruhan) }\end{array}$ \\
\hline $\begin{array}{l}\text { Umpan } \\
\text { balik }\end{array}$ & $\begin{array}{l}\text { Menghubungkan dan kolaborasi komunal serta } \\
\text { penemuan, terutama untuk pengguna non- } \\
\text { teknis. }\end{array}$ \\
\hline Konsensus & $\begin{array}{l}\text { Lapisan gamified menyediakan mekanisme } \\
\text { insentif. Sangat penting bagi mekanisme } \\
\text { insentif untuk mendapatkan konsensus semua } \\
\text { pengguna (sebagai salah satu prinsip dari } \\
\text { aplikasi desentralisasi yang transparan). } \\
\text { Mekanik game ini berisi status konsensus dari } \\
\text { semua pengguna yang terlibat }\end{array}$ \\
\hline
\end{tabular}

Ada lima kemungkinan mekanisme permainan di berbagai tingkat abstraksi yang disajikan pada Tabel 2 . Setiap implementasi model memerlukan penggunaan mekanisme permainan ini (serta tambahan yang akan datang) menggunakan semacam model vektor, di mana setiap dimensi sesuai dengan mekanik terpisah yang ditangani dalam kontrak pintar.

B. RQ2: Apa keberlanjutan jangka panjang yang diharapkan dari mekanisme konsensus berbasis game karena minat pengguna akhir mungkin berkurang dalam game saat ini?

Jika mining blockchain memutuskan untuk menggunakan gamifikasi daripada mekanisme gamifikasi bawaan, itu akan menjadi tanggung jawab platform hosting untuk memastikan bahwa substansi permainan antarmuka akan dipertahankan dengan baik dari waktu ke waktu dengan mengumpulkan analitik konstan untuk mendorong keputusan. Mempertahankan keberlanjutan game adalah kasus yang sama dengan semua game online di pasar. Mereka harus tetap kompetitif dan relevan untuk membuat penggunanya tetap terlibat.

\section{C. $R O Q 3$ : Bagaimana cara menjamin keamanan lapisan gamifikasi?}

Lapisan gamified harus jujur dan memiliki keamanan tinggi. Untuk menegakkan keamanan lapisan, kami menyarankan untuk menggunakan kontrak pintar sebagai blok penyusun untuk membuat implementasi lapisan yang tidak dapat diubah dan lebih aman (seperti yang dibahas di bagian sebelumnya). Kontrak pintar diamankan dengan desain, dan merupakan program pengarahan diri sendiri yang diimplementasikan melalui perangkat lunak yang eksekusi otonomnya menerapkan ketentuan penyelesaian dan logika bisnis dalam mekanisme permainan tertentu.

\section{KESIMPULAN}

Dalam sistem gamifikasi di dalam ruang lingkup blockchain suatu masalah terdapat berbagai aspek yang harus didukung dan dipertimbangkan, termasuk memahami masalah dan mengetahui target audiens lingkungan yang di-gamifikasi, menyesuaikan konteks untuk memenuhi kebutuhan yang berbeda. jenis kepuasan pemain, dan yang terpenting memiliki bermakna mekanisme permainan yang untuk menerapkan konsep gamifikasi. Untuk mendapatkan mekanisme game khusus blockchain yang sesuai, kami menguatkan berbagai elemen desain gamifikasi dan demografi untuk menjelajahi lingkungan blockchain. Kami mengidentifikasi elemen motivasi yang telah dimasukkan kedalam desain gamifikasi dan meninjau literatur tentang desain game dalam berbagai studi terbaru, terutama yang terkait dengan lingkungan pengembangan perangkat lunak Kedepannya yang diharapkan jika pengembang blockchain memutuskan untuk menggunakan game daripada mekanisme game bawaan, itu akan menjadi tanggung jawab platform hosting untuk memastikan bahwa substansi permainan antarmuka akan dipertahankan dengan baik dari waktu ke waktu dengan 
mengumpulkan analitik konstan untuk mendorong keputusan.

\section{UCAPAN TERIMA KASIH / ACKNOWLEDGMENT}

Penulis mengucapkan terimakasih kepada Universitas Raharja serta semua pihak yang telah memberikan izin, bimbingan serta memberikan dukungan kepada penulis sehingga penulis telah berhasil menyelesaikan penelitian ini .

\section{REFERENSI}

[1] Q. Aini, U. Rahardja, and A. Khoirunisa, "Blockchain Technology into Gamification on Education," IJCCS (Indonesian J. Comput. Cybern. Syst., vol. 14, no. 2, pp. 147-158, 2020.

[2] S. Hussain, S. Qazi, R. R. Ahmed, D. Streimikiene, and J. Vveinhardt, "Employees management: evidence from gamification techniques," Montenegrin J. Econ., vol. 14, no. 4, pp. 97-107, 2018

[3] K. Seaborn and D. I. Fels, "Gamification in theory and action: A survey," Int. J. Hum. Comput. Stud., vol. 74, pp. 14-31, 2015.

[4] J. Swacha, "Gamification in enterprise information systems: what, why and how," in 2016 Federated Conference on Computer Science and Information Systems (FedCSIS), 2016, pp. 12291233.

[5] P. Herzig, M. Ameling, and A. Schill, "A generic platform for enterprise gamification," in 2012 Joint Working IEEE/IFIP Conference on Software Architecture and European Conference on Software Architecture, 2012, pp. 219-223.

[6] G. Zichermann and C. Cunningham, Gamification by design: Implementing game mechanics in web and mobile apps. “O’Reilly Media, Inc.," 2011.

[7] A. L'Heureux, K. Grolinger, W. A. Higashino, and M. A. M. Capretz, "A gamification framework for sensor data analytics," in 2017 IEEE international congress on internet of things (ICIOT), 2017, pp. 74-81.

[8] T. G. Papaioannou et al., "IoT-enabled gamification for energy conservation in public buildings," in 2017 Global Internet of Things Summit (GIoTS), 2017, pp. 1-6.

[9] F. García, O. Pedreira, M. Piattini, A. Cerdeira-Pena, and M. Penabad, "A framework for gamification in software engineering," J. Syst. Softw., vol. 132, pp. 21-40, 2017.

[10] F. Agustin, F. P. Oganda, N. Lutfiani, and E. P. Harahap, "Manajemen Pembelajaran Daring Menggunakan Education Smart Courses," TMJ (Technomedia Journal) Vol. 5 No. 1 Agustus 2020, p. 40, 2021.

[11] D. Kayımbaşığlu, B. Oktekin, and H. Hacı, "Integration of gamification technology in education," Procedia Comput. Sci., vol. 102 , pp. 668-676, 2016

[12] C. H.-H. Tsay, A. Kofinas, and J. Luo, "Enhancing student learning experience with technology-mediated gamification: An empirical study," Comput. Educ., vol. 121, pp. 1-17, 2018.

[13] J. C. Paiva, J. P. Leal, and R. Queirós, "Odin: A service for gamification of learning activities," in International Symposium on Languages, Applications and Technologies, 2015, pp. 194-204.

[14] J. C. Paiva, J. P. Leal, and R. Queirós, "Gamification of learning activities with the Odin service," Comput. Sci. Inf. Syst., vol. 13, no. 3, pp. 809-826, 2016.
[15] J. C. Paiva, J. P. Leal, and R. A. P. de Queirós, "Design and implementation of an IDE for learning programming languages using a gamification service," in Gamification-Based E-Learning Strategies for Computer Programming Education, IGI Global, 2017, pp. 295-308.

[16] M. Z. H. Kolpondinos and M. Glinz, "Tailoring gamification to requirements elicitation: A stakeholder-centric motivation concept," in 2017 IEEE/ACM 10th International Workshop on Cooperative and Human Aspects of Software Engineering (CHASE), 2017, pp. 9-15.

[17] F. Kifetew, D. Munante, A. Perini, A. Susi, A. Siena, and P. Busetta, "Dmgame: A gamified collaborative requirements prioritisation tool," in 2017 IEEE 25th International Requirements Engineering Conference (RE), 2017, pp. 468-469.

[18] R. M. Parizi, "On the gamification of human-centric traceability tasks in software testing and coding," in 2016 IEEE 14th International Conference on Software Engineering Research, Management and Applications (SERA), 2016, pp. 193-200.

[19] R. M. Parizi, A. Kasem, and A. Abdullah, "Towards gamification in software traceability: Between test and code artifacts," in 2015 10th International Joint Conference on Software Technologies (ICSOFT), 2015, vol. 1, pp. 1-8.

[20] G. Fraser, "Gamification of Software Testing. En 2017 IEEE/ACM 12th International Workshop on Automation of Software Testing (AST)(pp. 2-7)," IEEE. https://doi. org/10.1109/AST, 2017

[21] E. Herranz, R. C. Palacios, A. de Amescua Seco, and M.-L. Sánchez-Gordón, "Towards a Gamification Framework for Software Process Improvement Initiatives: Construction and Validation.," J. UCS, vol. 22, no. 12, pp. 1509-1532, 2016.

[22] E. Herranz, R. Colomo-Palacios, and A. Al-Barakati, "Deploying a gamification framework for software process improvement: preliminary results," in European Conference on Software Process Improvement, 2017, pp. 231-240.

[23] D. Ašeriškis and R. Damaševičius, "Gamification of a project management system," in Proc. of Int. Conference on Advances in Computer-Human Interactions ACHI2014, 2014, pp. 200-207.

[24] J. Swacha, "Gamification in knowledge management: motivating for knowledge sharing," Polish J. Manag. Stud., vol. 12, 2015.

[25] J. Hamari, J. Koivisto, and H. Sarsa, "Does gamification work?--a literature review of empirical studies on gamification," in 2014 47th Hawaii international conference on system sciences, 2014, pp. 3025-3034.

[26] R. M. Parizi and A. Dehghantanha, "On the understanding of gamification in blockchain systems," in 2018 6th International Conference on Future Internet of Things and Cloud Workshops (FiCloudW), 2018, pp. 214-219.

[27] E. P. Harahap, Q. Aini, and R. K. Anam, "Pemanfaatan Teknologi Blockchain pada Platform Crowdfunding," Technomedia J., vol. 4 no. 2, pp. 199-210, 2020.

[28] D. E. Standard, "Federal information processing standards publication 46," Natl. Bur. Stand. US Dep. Commer., vol. 23, 1977.

[29] U. Rahardja, E. P. Harahap, and D. D. Christianto, "Pengaruh Teknologi Blockchain Terhadap Tingkat Keaslian Ijazah," Technomedia J., vol. 4, no. 2, pp. 211-222, 2020.

[30] B. Morschheuser, L. Hassan, K. Werder, and J. Hamari, "How to design gamification? A method for engineering gamified software," Inf. Softw. Technol., vol. 95, pp. 219-237, 2018. 